\title{
The Effect of Business Process Re-Engineering on Organizational Performance: The Mediating Role of Information and Communications Technology
}

\author{
Aysar Mohammad Khashman ${ }^{1}$ \\ ${ }^{1}$ Department of Management, The World IslamicScience and EducationUniversity (WISE), Jordan \\ Correspondence: Aysar Mohammad Khashman, Department of Management, The World IslamicScience and \\ EducationUniversity (WISE), Jordan. E-mail: aysarmak@yahoo.com
}

Received: May 29, 2019

Accepted: June 30, 2019

Online Published: August 5, 2019

doi:10.5539/ijbm.v14n9p132

URL: https://doi.org/10.5539/ijbm.v14n9p132

\begin{abstract}
The purpose of this study is to attempt to highlight the factors of business process reengineering (BPR) processes that effect on organizational performance in the Drivers and Vehicles License Department (DVLD) in Jordan through using ICT as a mediating role. From previous studies, five factors of BPR were adopted for this study, including "Ability to change, Selecting BPR Methodology, Organizational Culture, BPR strategic alignment, and Top management support ". ICT was used as an intermediary role for this structure to promote organizational performance. The study used the PLS software to analyze the basic relationships amongst the most relevant combinations between BPR, ICT, and Organizational Performance with a total of five constructs. As a result of the findings of operational, middle, and top levels $(\mathrm{n}=124)$ working in Drivers and Vehicles License Department (DVLD), it was awarded the King Abdullah II Award for Excellence in Jordan for 2018. It was found that there was a strong and statistically positive significant relationship between several variables of business process reengineering and organizational Performance by using the ICT as a mediating variable.
\end{abstract}

Keywords: business process re-engineering, information \& communications technology, organizational performance

\section{Introduction}

Today, Business Process Re-engineering (BPR) has become a necessity in the business world, because it is considered as one of the main methods which lead to modifications and development in the business processes. (Tka \& Ghannouchia, 2012). BPR is determined as one of the most important solutions for organizational improvements in all business processes and performance measures. However, it reported high failure rates of $70 \%$ when using it, and the main reason behind this is that the process tends to be focused on, regardless of the surrounding environment and the knowledge of the organization. The other reasons are due to the lack of tools to identify the causes of the contradictions and inefficiencies (Abd Ellatif., et al. 2017). Today, the business world is full of companies that have been greatly affected by fluctuations in the business environment around the world and customers' needs and preferences have greatly changed. Therefore, in light of these fluctuations, and for survival of the organizations, a new approach is required by business managers to find a way to rethink new and more efficient ways to manage business and minimize cost and maximize profits (Ogbo., et al, 2015). For this, BPR has been suggested as an effective managerial tool to deal with technological changes as well as marketing changes in today's competitive markets. It leads to minimized activity costs across the process or the organization as a whole organization by analyzing and redesigning work flow and processes within and outside the organization (Omidia \& Khoshtinata, 2016). Re-engineering of operations was introduced for the first time by Hammer and Chmpy (1993), it was as "the Basic re-thinking and radical design of the new processes In order to achieve amazing improvements in contemporary critical measures, such as price, quality of service and speed (Omidia \& Khoshtinata, 2016). This means that current processes are reviewed and redesigned carefully in order to make the function of an organization more effective and efficient. It should be supported through the modeling process because it is necessary to specify the process in the context of business processes re-engineering where organizations are comparison business process models to determine common operational aspects and differences. e.g, it is essential when organizations are merged to determine and settle the differences between their operations, and when the organization needs to verify whether its operations conforms to an organization-wide or 
industry-wide standard. Applying this, organizations will find improvements to cure problems or gaps in its processes (Tka, M.\&.,Ghannouchia, S., 2012). indeed, BPR requires synchronized redesign of processesand support of information systems (IS) to achieve significant improvements in cost, quality, time, and customer attention to products (goods \& services) (Omidia, \&., Khoshtinata, B, 2016). For that reason, organizations are actively taking initiatives to differentiate their services to their customers in different ways to meet the expectations of their customers. The improvements of these processes helps organizations satisfy their loyal customers and provides them with the ability to survive and operate in the long term. This Paper aims to contribute to this field by identifying the effect of BPR on organizational performance with the role of information and communications technology as a mediating variable.

\subsection{Problem Statement and Objective}

BPR does not only mean the change required by organization, this change must also be exciting (Balasubramanian, 2010). For this, the concept of business re-engineering is considered as one of the modern management methods aimed at making radical and integrated changes in the operations and activities of organizations across all industries. It is noted that many organizations do not realize the importance of applying this concept, despite the role of it in improving and developing their activities and operations. Therefore, the following research questions were designed to try to achieve the study objective:

\subsection{Research Question}

To what extent can re-engineering of business processes affect organizational performance using ICT as an intermediary role?

\subsection{The Objective of This Study}

To determine to what extent BPR cans influence organizational performanceby using ICT as a mediating role.

\section{Theoretical Framework}

\subsection{Business Process Re-engineering Definitions}

Many authors attempted to explain BPR, but it is important to note that the world is heading towards global competition and companies and institutions worldwide are adopting strategies and mechanisms to understand the impact of re-engineering on a variety of variables such as service, quality, cost and cycle time. The concept of re-engineering was introduced in the early 1990s of the last century, specifically in the year 1993 by Michael Hammer and James Chambi in there their book titled: A Statement of The Re-Engineering Structure of A Revolution In The Business World. They defined re-engineering as a the basic re-thinking and redesigning the business processes to

achieve significant improvements in contemporary measures of performance such as cost, time, quality, service and speed (Isakhani \& Mir-Ghaderi, 2011). BPR has been used since 1990 and has widely achieved many advantages, such as, increased production, lower costs, improved products and increased customer satisfaction. There are many different definitions of reengineering and these definitions differ in terms in focus. BPR has been defined as a "drastic redesign of processes for significant improvements in costs, quality and services"(AbdEllatif, et al., 2017). Furthermore, BPR is a process that is used to make drastic changes in organization and places great considerably on changes in the organizational processes, job and behavioral components of the organizations. Lila., et al. (2012) defined BPR as " essential rethinking and radical redesign of business processes to achieve basic improvements in all performance metrics such as cost, quality, service, and speed. Ozcelik, Y. (2013) also defined BPR as a radical redesign of processes in order to obtain great improvements in cost, service, and quality, which range from customer relationship management (CRM) for fulfilment, and from assembly lines to logistics services. In addition, BPR is defined as "methodologies for changing an organization's internal business in response to requirements and changes of environmental" (AbdEllatif., et al. 2017). It has also been labelled as "a set of logically related tasks using the company's resources to provide customer oriented results to support the organization's goals" (Vergidis., et al. 2008). All these definitions contain the following keywords: fundamental, radical, exciting and practical, implying that it is important to re-understand the process and the basic business process before reengineering it while ignoring the fundamental rules and assumptions of traditional or old business processes and radically redesigning the business process for dramatic performance in terms of cost, time, quality, and speed. While re-engineering achieved significant improvements in organization performances and not just work adjustments. However, many BPR projects result in significant changes in key organizational structures and processes, but may not achieve all the desired or expected outcomes (Isakhani \& Mirghaderi, 2011). 


\subsection{Business Process Re-engineering Factors}

The factors of BPR in the this study have been adapted on the basis of the area of the study and its appropriateness with the Drivers and Vehicles License Department (DVLD) in the Hashemite Kingdom of Jordan, which is in line with previous studies. In order to complete this study, the following BPR factors were identified as independent variables, which are as follows:

A. Organizational Culture: Culture it has been recognized as a Critical Success Factors (CSF) for the implementation of BPR (Salimifard et al., 2010; Abdolvand et al., 2008; Reijers \& Mansar, 2005; Maull et al., 2003; Crowe et al., 2002 ). Coordination, employees involvement, Positively and friendly interactions are the standard feature of an innovative culture in the organization. In addition,effective utilization of employees ideas enable organizations to achieve positive results.

B. Top Management Support (Leadership): Leadership plays a pivotal role in efforts to review the work methods (Ahadi, 2004). The role of leadership is: monitoring and controlling all activities related to change, and this is extremely important. Hammer and Champy (1993) cited obstacles in leadership as the cause of most failures in changing business processes. One of these obstacles is how to eliminate political issues between regulatory boundaries; providing an appropriate structure of compensation, resolving disputes between managers and leading IT organizations can only carried out with top management efforts. also top management power can be an effective in starts of change and in implementation.

C. BPR Methodology: Many various methodologies have been developed to support changing in business process projects (Mansar et al., 2003). According to Valiris and Glykas, (1999) The methodology is an organized set of techniques, procedures and tools developed to deal with a single project life cycle to achieve its goal and reduce problems and difficulties .

D. Strategic Alignment: De Bruin and Rosemann (2006) considers Strategic alignment of BPR as "the continuing interrelationship of organizational priorities and institutional processes that enable the achievement of business objectives. O'Neill and Sohal (1998) said that If the objectives of BPR are defined on the basis of strategic direction they will help organizations achieve long-term benefits. In fact, BPR can be considered in this way as a tool for implementing the strategy (De Bruin \& Rosemann, 2006).

E. Ability to Change: One of the major drawbacks of successful implementation of process reengineering is the resistance to various changes that occur in the organization. and this requires effective management to managing change that is defined as "the methods that management and leadership use to keep employees and encourage them to learn and grow continuously, accept change, create conditions and opportunities for organizational change ". (Omidia \& Khoshtinata, 2016).

\subsection{Information, Communication Technology (ICT) Concept}

ICT is a critical element in BPR. Thus, many researchers consider it to be enabling changes in work processes and collaboration both within organizations and with other organizations. However, according to Larsen (2003), ICT is widely accepted at the organizational level to increase the efficiency and effectiveness of the organization in terms of costs and competitiveness, so the integration of ICTs is essential In the functions of organizations. Hammer (1990) emphasized the need to apply modern computers and communication technology to overcome the challenges inherent in business processes. Thus, BPR should benefit from IT as a competitive advantage in strategic planning. Hammer stresses that the composition of IT infrastructure components is a critical determinant of how information resources can be connected. An effective IT infrastructure should use a top-down approach of the business strategy and supporting strategies. And to achieve the expected results in the implementation of business process reengineering, there is a need for appropriate IT infrastructure in most projects because BPR starts from the IT department, and IT is a natural partner of BPR and it plays a vital and central role in success of BPR projects (Crowe et al., 2002; Salimifard et al., 2010). IT not only accelerates the process that is being implemented but also its integrated processes reduce errors and thus improves productivity (Reijers \& Mansar, 2005). Therefore, IT should therefore be viewed as an important mechanism for fundamentally restructuring the working method. For this, information and communication technology is considered as a natural factor in business process reengineering and an important component and it has a large and continuous role in the success of BPR projects. Abd Ellatif et al. (2017) stated that ICTs include the areas of the information system and communication technology which provide members with the necessary and required information which brings the effectiveness of the business and organization together.

The advantages of ICT:

- Making information available anywhere by sharing a database. 
- The Use of telecommunications networks allowing the organization to be centralized and decentralized at the same time.

- Identification and automatic tracking which allowing things to be easily established.

\subsection{Organizational Performance}

Organizational performance is an indicator of performance assessment achieved by the organization in a particular period (Abubakar, 2016). The evaluation of organizational performance is a measure of the effectiveness and efficiency of organizations, It is said that the organization's performance is good if the results achieved show an increase in achievement better than the previous period. In other words, how successful is the organization in achieving its objectives? The main goal of most business organizations is to reduce costs and maximize profits. Other objectives include growth, increased sales, market share, and improved productivity in terms of better quality, greater quantities of goods and services, customer satisfaction, organizational development, individual improvement... etc. (Aregbeyen, 2011).

It is certain that all organizations have a common goal, how to compete in the business environment and how to win competition and achieve competitive advantage. To achieve this goal, organizations are required to be flexible in responding to environmental change and developing the existing business environment through organizational transformations and to pursue a variety of approaches, including: re-engineering their operations, rethinking their way of thinking, and restructuring organizational designs which has been developed in the literature of modern management, in order to improve its performance and maintain its position in the market. Therefore, many of the modern management techniques aimed to developing activities and processes in companies are working to increase productivity, the most important method of these methods is business re-engineering (Shaqqour \& Al- Kassar (2016).

\subsection{The Important of BPR for Organizational Performance}

The business process perspectives emphasize the relationship between business processes improvement and organizational performance, It argues that achieving highest business processes improvement and highest business performance is results in greater overall organizational performance (Kohli \& Hoadley, 2006; Skrinjar et al., 2008). According to Nadeem and Ahmad (2016) the BPR team has the competencies, ability, and expertise to change overall processes of administration and businesses, and the organizations with strong BPR support and information technology support are more valuable and have a positive relationship with the customers, because when business processes are redesigned and implemented effectively will lead to enhancing the organization performance. Debela (2009) Showed that fundamentally redesigned processes have a positive relationship between the organization's operations and performance, as it will improve business efficiency and productivity and increase profitability as a result of the execution and completion of business process reengineering processes. were Ahadi (2004), which aimed to illustrate the effect of BPR resources on organizational performance. The results of this study found that resources, senior management support, change management, centralized decision making and formalization of procedures had positive linkages with the success of BPR. Another study conducted by Ogbo et al. (2015) on business process reengineering and performance of commercial banks in nigeria, the study found the following results: The speed boosted the profitability of commercial banks to a large extent; there was a positive relationship between restructuring organizations and advantage. In conclusion, organizations that adopt business process re-engineering have a different level of success, and the success of an individual organization depends on the balance between the organizational structure of the organization and the environment. In another study by Akam et al, (2018)that examined the effect of BPR resources on performance of brewing firms in Nigeria where the results of this study showed that financial and technological resources were in proper use while human resources were moderate. Also, the performance of companies currently has a top five-point rating as BPR resources have a significant impact of $94 \%$ on corporate performance. Specifically, a positive impact was established so that financial resources $(63 \%)$ have a greater impact, followed by human resources $(20 \%)$ and then technology $(19 \%)$. This means that using resources is a real strategy to enhance the company's performance and Companies that follow the current wave of technological innovations will enhance their competitiveness and survival rate. The study concluded that BPR is a real tool to enhance employee satisfaction, teamwork, cooperation and quality of service delivery as well as achieving organizational strategic objectives in companies.

\subsection{Relationship between BPR, ICT and Organizational Performance}

Business operations have been the focus of the IT community since the early $1960 \mathrm{~s}$, where information technology is often used to automate defferent processes, (Davenport, 2008). Although advanced information systems and IT infrastructure were developed and deployed to automate business processes, the expected 
benefits have not been realized due to the simple automation of non-value additions (Davenport \& Short 1990; Hammer 1990). BPR approach, with one response is the appearance of BPR, as an innovation- based process (Davenport \& Short Hammer, 1990). The first introduced of the concept of BPR was in 1990 by Hammer among his article "Re-engineering Work: Do not automate, obliterate". BPR was adopted as a process based innovation, resulting in a significant improvement in performance through drastic re-design of the core of processes of organizations (Hammer 1990; Davenport \& Short 1990). Since its adoption in the 1990s, many companies have rapidly adopted BPR methods. BPR letters increased significantly (Wang 2008). Many researchers have identified the relationship between BPR, ICT and organizational Performance, where Albadvi et al. (2007) and Ahmad et al. (2007) explained that. The size and the type of information technology deployed and the extent of business process change have a positive and a strong effect on organizational Performance. While Devaraj and Kohli (2000) Pointed out that, The combined effect of changing the process and investment in IT has a strong and positive impact on organizational performance. Kassahun and Molla (2011) said that the broader and deeper the BPR level of change, the greater its impact on organizational performance, Information technology deployment accompanied by a process redesign has a strong and positive effect on productivity. Kohli \& hoadley (2006) and Skrinjar et al. (2008) contend that process level success leads to increased impact on organizational performance. BPR project management and infrastructure of IT have a strong and positive relationship with organizational performance. Willcocks (2002), mention that the massive investment in IT has achieved significant earnings in organizational performance.

\section{Research hypothesis and Study Model}

This study designed the following model includes the research variables: BPR as independent variables (Ability to change, Selecting BPR Methodology, Organizational Culture, BP strategic alignment, and Top management support), ICT is mediating variable, and Organizational Performance is dependent. As shown in Figure 1 below:

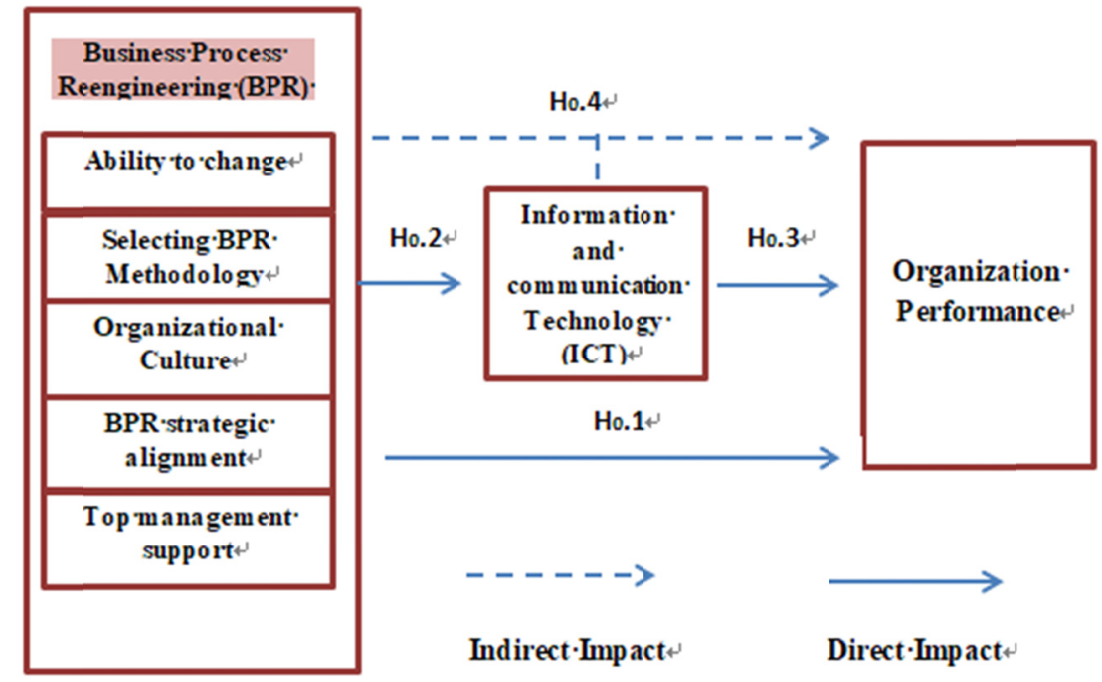

$\mathrm{J}$

Figure 1. Research model

In order to achieve the purpose and to solve the problem of this study, the following hypotheses were formulated and tested.

First, direct effects of Business Process Re-engineering factors and Organizational Performance in the H1. H1 is Contains five sub-hypotheses as follows:

H1.1: Ability to change has an impact on Organizational Performanceat $(\alpha \leq 0.05)$.

H1.2: Selecting BPR Methodology has an impact on Organizational Performanceat $(\alpha \leq 0.05)$.

H1.3: Organizational Culture has an effects on Organizational Performanceat $(\alpha \leq 0.05)$.

H1.4: BPR strategic alignment has an impact on Organizational Performanceat $(\alpha \leq 0.05)$.

H1.5: Top management support has an impact on Organizational Performanceat $(\alpha \leq 0.05)$. 
Second, the direct effects of Business Process Re-engineering and Information and communication Technology (ICT) in $\mathrm{H} 2$. Thus, $\mathrm{H} 2$ is Contains five sub hypotheses as follows:

H2.1: Ability to change has an effects on ICT at $(\alpha \leq 0.05)$.

H2.2: Selecting BPR Methodology has an effects on ICT at $(\alpha \leq 0.05)$.

H2.3: Organizational Culture has an effects on ICT at $(\alpha \leq 0.05)$.

H2.4: BPR strategic alignment has an effects on ICT at $(\alpha \leq 0.05)$.

H2.5: Top management support has an effects on ICT at $(\alpha \leq 0.05)$.

Third, the direct effects of (ICT) and Organizational Performance in the $\mathrm{H} 3$ as follows:

H3.1: ICT has an effects on Organizational Performanceat $(\alpha \leq 0.05)$.

Finally: indirect effect between BPR by (ICT) on Organizational Performance. Thus, H4 is Contains five sub hypotheses as follows:

H4.1: ICT has a mediation role between Ability to change and Organizational Performance at ( $\alpha \leq 0.05)$.

H4.2 ICT has a mediation role between Selecting BPR Methodology and Organizational Performance at ( $\alpha \leq$ $0.05)$.

H4.3: ICT mediation role between Organizational Culture and Organizational Performance at $(\alpha \leq 0.05)$.

H4.4: ICT has a mediation role between BPR strategic alignment and Organizational Performance at $(\alpha \leq 0.05)$.

H4.5: ICT has a mediation role between Top management support and Organizational Performance at $(\alpha \leq 0.05)$.

\section{Research methodology}

This study applied the quantitative method. In addition, the questionnaire was used to collect data relating to the proposed model, to explore the impact of business processes reengineering on organizational performance using ICT as mediating role in the Drivers and Vehicles License Department (DVLD) which was awarded the King Abdullah II Award for Excellence in Jordan for 2018 (See Appendix 1). In addition, this study used Smart Partial Least Square (PLS) program to analyze basic relationships between the most relevant structures to find indirect and direct impact between all combinations.

\section{Data analysis and Result}

\subsection{The Study Sample}

The sample of this study was all employees of the Drivers and Vehicles License Department (DVLD) operating in the central region, which included the areas of Amman, Balqa, Madaba and Zarqa governorates in the Hashemite Kingdom of Jordan as a simple

random sample for this study. Total of (150) questionnaires were sent to these organizations. A total of (132) responses were returned to the questionnaire, and after the verification of the recovered questionnaires, (124) were found to be valid for analysis. This sample is considered acceptable for the purposes of analysis because it is located between (30-500) according to Sikaran, U. (2006).

\subsection{Results of Demographic Data}

The Demographic results show that 76 respondents were male while 48 were females.In addition, the largest age group of (50 respondents) ranged from 30- Less than 35 years old. While the smallest group of (10 respondents) was under 25 years old. Furthermore, The largest group of managerial levels was the operational management (96 people surveyed). The lower group was Middle management (13 respondents). The largest experience group of (58 respondents) pointed that their years of experience ranged from 10- Less than 15 years. Finally, the smallest experience group of ( 3 respondents) pointed that their years of experience was less than 5 year. These demographic data are detailed below in Table 1. 
Table 1. Demographic data results

\begin{tabular}{llll}
\hline description & variable & result & percentage \\
\hline Gender & Male & 76 & $61.3 \%$ \\
& Female & 48 & $38.7 \%$ \\
Age & Less than 25 year's & 10 & $8.1 \%$ \\
& 25- Less than 30 year's & 24 & $19.4 \%$ \\
& 30- Less than 35 year's & 50 & $40.3 \%$ \\
Managerial level & More than 35 year's & 40 & $32.3 \%$ \\
& Operational management & 96 & $77.4 \%$ \\
& Middle management & 13 & $10.5 \%$ \\
& Top management & 15 & $12.1 \%$ \\
Years of experience & Less than 5 year's & 3 & $2.4 \%$ \\
& 5- Less than 10 year's & 27 & $21.8 \%$ \\
& 10- Less than 15 year's & 58 & $46.8 \%$ \\
& More than 15 year's & 36 & $29.0 \%$ \\
\hline
\end{tabular}

\subsection{Measurements Analysis}

This study used a program of Smart Partial Least Square (PLS) to test all hypotheses and to explain direct and indirect effect of business process re-engineering as independent variables (Ability to change, Selecting BPR Methodology, Organizational Culture, BPR strategic alignment, and Top management support), Information and communications technology as mediating variable, and organizational performance as dependent.

\subsection{Path loading for Proposed Model}

The following figure shows the Smart Partial Least Square (PLS) path modeling estimation of the proposed model (Figure 2).

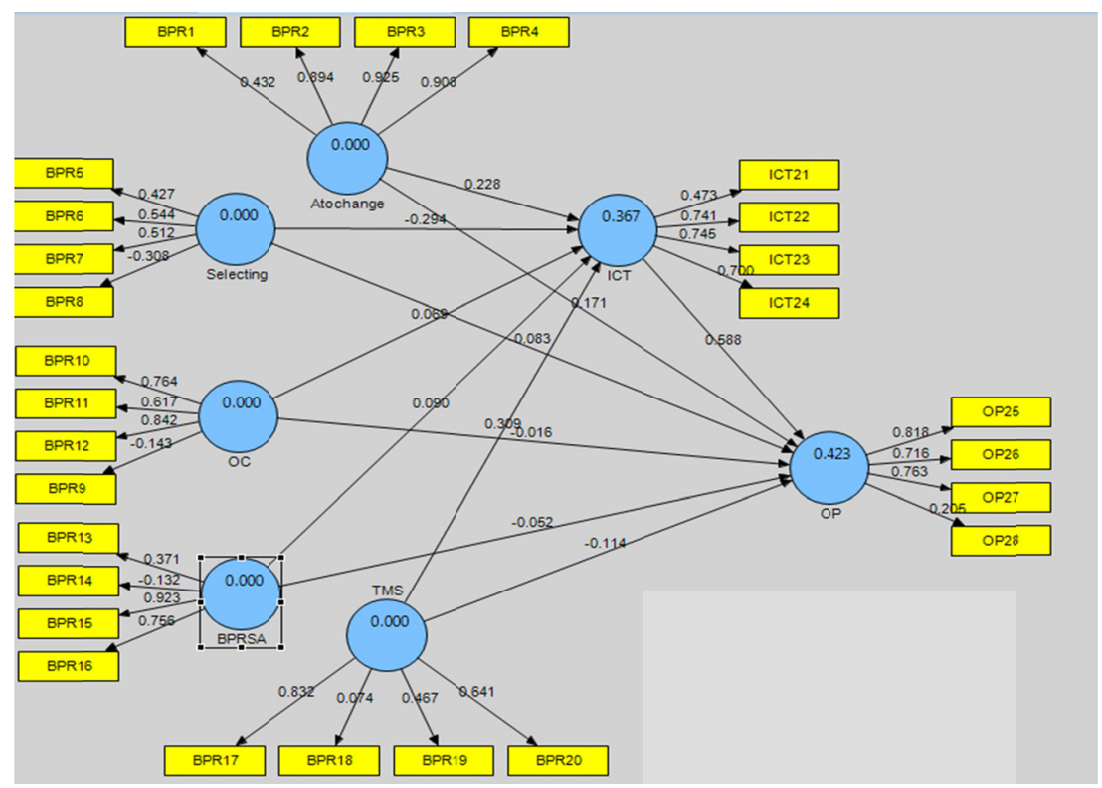

Figure 2. Path loadings for proposed model

Figure 2 contains seven elements (Ability to change, Selecting BPR Methodology, Organizational Culture, BPR strategic alignment, and Top management support) as Independent variable, Information and communications 
technology as mediating variable, and organizational Performance as dependent. See table (2) that shows the research constructs Factor Loading.

Table 2. Measurement of constructs

\begin{tabular}{|c|c|c|c|}
\hline Variables & Item & Factors Loading & Result \\
\hline \multirow[t]{4}{*}{ Ability to change } & PBR1 & 0.43 & Not accept \\
\hline & PBR2 & 0.89 & accept \\
\hline & PBR3 & 0.92 & accept \\
\hline & PBR4 & 0.90 & accept \\
\hline \multirow[t]{4}{*}{ Selecting BPR Methodology } & PBR5 & 0.42 & Not accept \\
\hline & PBR6 & 0.54 & accept \\
\hline & PBR7 & 0.51 & accept \\
\hline & PBR8 & -0.30 & Not accept \\
\hline \multirow[t]{4}{*}{ Organizational Culture } & PBR9 & -0.14 & Not accept \\
\hline & PBR10 & 0.76 & accept \\
\hline & PBR11 & 0.61 & accept \\
\hline & PBR12 & 0.84 & accept \\
\hline \multirow[t]{4}{*}{ BPR strategic alignment } & PBR13 & 0.37 & Not accept \\
\hline & PBR14 & -0.13 & Not accept \\
\hline & PBR15 & 0.92 & accept \\
\hline & PBR16 & 0.75 & accept \\
\hline \multirow[t]{4}{*}{ Top management support } & PBR17 & 0.83 & accept \\
\hline & PBR18 & 0.07 & Not accept \\
\hline & PBR19 & 0.46 & Not accept \\
\hline & PBR20 & 0.64 & accept \\
\hline \multirow{4}{*}{$\begin{array}{l}\text { Information } \\
\text { technology }\end{array}$} & ICT21 & 0.47 & Not accept \\
\hline & ICT22 & 0.74 & accept \\
\hline & ICT23 & 0.74 & accept \\
\hline & ICT24 & 0.69 & accept \\
\hline \multirow[t]{4}{*}{ Organizational Performance } & OP25 & 0.81 & accept \\
\hline & OP26 & 0.71 & accept \\
\hline & OP27 & 0.76 & accept \\
\hline & OP28 & 0.20 & Not accept \\
\hline
\end{tabular}

The path loadings for all variables exceed the value of $(0.50)$ without the factors (BPR1, BPR5, BPR8, BPR9, BPR13, BPR14, BPR18, BPR19, ICT21, OP28) and therefore, other Factors associated with the search model were corrected and accepted for analysis (Fornell \& Larcker, 1981).

5.5 Path Loading for Modify Model

At first, the Ability to change items (PBR1), Selecting BPR Methodology item (PBR5 and PBR8), Organizational Culture item (PBR9), BPR strategic alignment item (PBR13 and PBR14), Top management support item (PBR18 and PBR19), Information and communications technology item(ICT21), and organizational performance item (OP28)was deleted.

The standardised path loadings for all indicators were higher than 0.50 and therefore they are all significant (Fornell \& Larcker, 1981).

All path loadings (as a result of factor analysis) are depicted in the model in Fig. 3. 


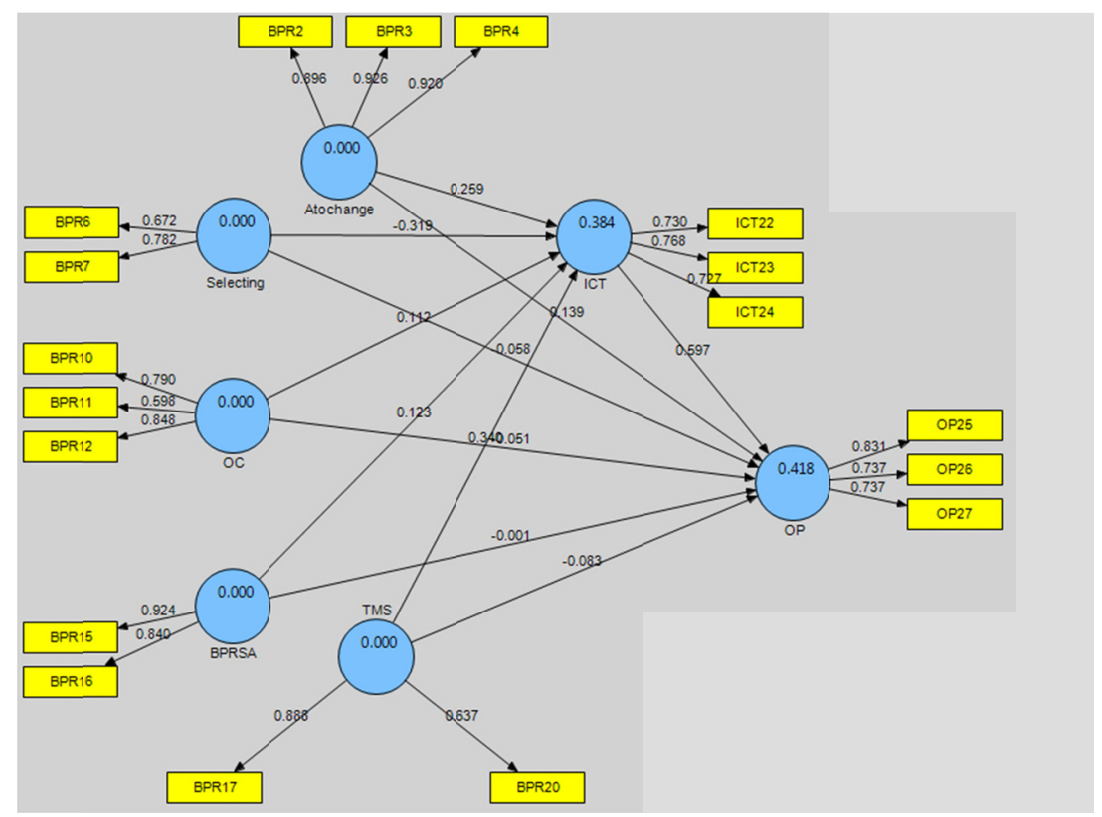

Figure 3. Path loadings for modify model

Based on Figure 3, All items are accepted because the standardised path loadings indices were above 0.5 and therefore all items are significant (Fornell \& Larcker, 1981).

\subsection{Reliability \& Validity}

It is essential to prove the validity and reliability of the constructs to complete the examination of the structural study model. Table (3) shows the various elements of reliability and validity which must be verified and report when PLS-SEM is conducted.

Table 3. Reliability and Validity

\begin{tabular}{|c|c|c|c|}
\hline Constructs & $\begin{array}{l}\text { Cronbach } \\
\text { Alpha (Ca) }\end{array}$ & $\begin{array}{ll}\text { Average } & \text { Variance } \\
\text { Extracted (Ave) } & \end{array}$ & Composite Reliability (Cr) \\
\hline Ability to change & 0.90 & 0.77 & 0.93 \\
\hline Selecting BPR Methodology & 0.70 & 0.55 & 0.87 \\
\hline Organizational Culture & 0.69 & 0.56 & 0.78 \\
\hline BPR strategic alignment & 0.65 & 0.59 & 0.79 \\
\hline Top management support & 0.65 & 0.53 & 0.81 \\
\hline Information and communications technology & 0.67 & 0.59 & 0.69 \\
\hline Organizational Performance & 0.71 & 0.77 & 0.74 \\
\hline
\end{tabular}

Table 3 shows the result of cronbach alpha (CA), the result of composite reliability (CR), and the result of average variance extracted (AVE) for all constructs of the model. the Internal consistency reliability: Kronbach Alpha was used as the lower bound of internal consistency reliability. All CA and C'R scores exceeded the recommended value of 0.65 (Nunnally \& Bernstein, 1994) indicating that all constructs have a good reliability. To verify convergent validity, (AVE) is evaluated for each latent variable. by returning to Table 3, all AVE values were found to be greater than the acceptable limit of 0.5 (Fornell \& Larcker, 1981). All AVEs, shown in Table 3 , ranged from 0.69 to 0.93 , so all variables meet convergent validity.

\subsection{Test of $R$ (Square)}

We need to apply the R Square test to demonstrate the relationships between BPR independent variables (Ability to change, Selecting BPR Methodology, Organizational Culture, BPR strategic alignment, and Top management support) with or without Information and communications technology as mediating variable, and organizational Performance as the dependent. Look to table 4. 
Table 4. R (Square) value

\begin{tabular}{l}
\hline Relation \\
\hline $\begin{array}{l}\text { Relation between BPR constructs and Organizational Performance without mediating by Information and communications } 0.38 \\
\text { (Square) }\end{array}$ \\
$\begin{array}{l}\text { Rechnology } \\
\text { technology. }\end{array}$
\end{tabular}

According to Table 4. The value of $\mathrm{R}$ (Square) to the variable of Business Process Re-engineering (BPR) and Organizational Performance without using Information and communications technology (IT). as a mediating variable was $(0.38)$ it was higher than $(25 \%)$, which determines a satisfactory and accepted predictive level based on recommended by (Gaur \& Gaur, 2006). On the other indicator; the value of R (Square) that is associated with (Business Process Re-engineering) constructs and Organizational Performance with using Information and communications technology as a mediation variable it was (0.42) so it was above (25\%), which defines a satisfactory and accepted prediction level based on recommended by (Gaur \& Gaur, 2006). Furthermore, the value of $\mathrm{R}$ (Square) is changed from (38\% to $42 \%$ ), which means the Information and communications technology The variable $\mathrm{R}$ (square) ratio is increased by around $4 \%$ when used as a mediating variable (ICT) in the proposed organizational performance model.

\subsection{Hypotheses Test}

We apply two phase to find the direct effect and indirect between all constructs and to test hypotheses.

First: By implementing the Bootstrapping analysis in PLS software find that the T-value of all Business Process Re-engineerin constructs on Organizational Performance without using Information and communications technology as a mediating variable. Figure 3 represente (T value) for this relation.

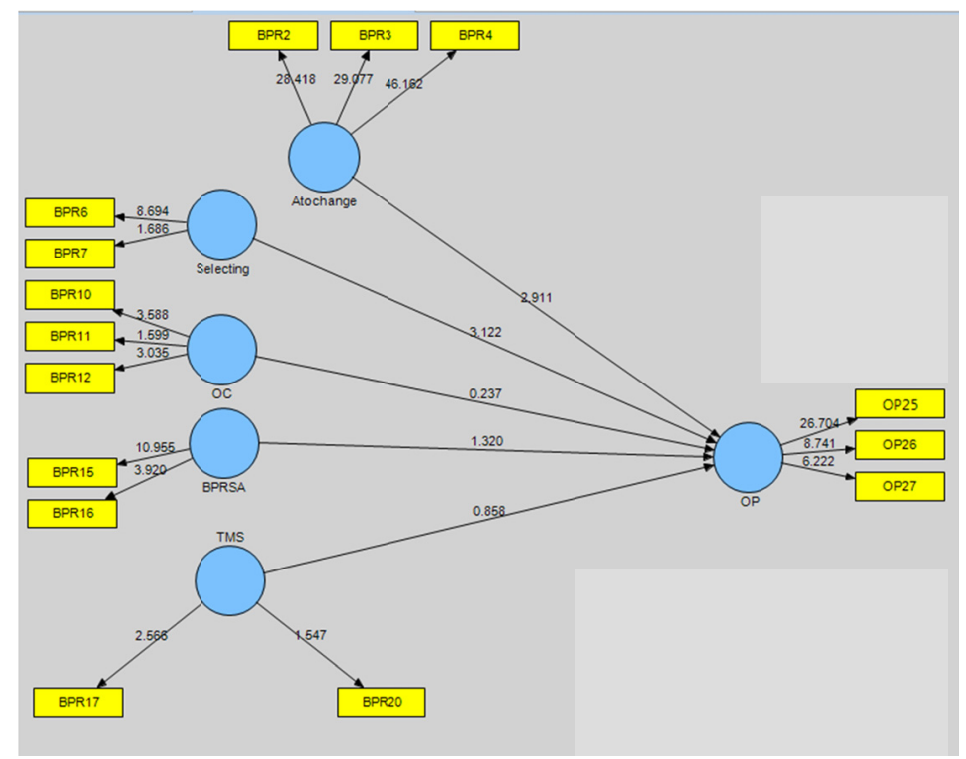

Figure 3. Business Process Re-engineerin constructs on Organizational Performance without using Information and communications technology as a mediation variable

According to Figure 3, this study presented ( $T$ value) to test the hypothesis of the five Business Process Reengineering constructs as independent variables (Ability to change, Selecting BPR Methodology, Organizational Culture, BPR strategic alignment, and Top management support) on Organizational Performance without using Information and communications technology as a mediating variable. refer Table 5. 
Table 5. Test results of Business Process Re-engineer in constructs and Organizational Performance without using Information and communications technology

\begin{tabular}{lll}
\hline Relation /The direct effect & T value & Beta value \\
\hline Ability to change and Organizational Performance & 2.911 & 0.13 \\
Selecting BPR Methodology and Organizational Performance & 3.122 & -0.05 \\
Organizational Culture and Organizational Performance & 0.237 & -0.06 \\
BPR strategic alignment and Organizational Performance & 1.320 & 0.00 \\
Top management support and Organizational Performance & 0.858 & -0.083 \\
\hline
\end{tabular}

Table 5 explained; H1.1. Ability to change has a significant effect on Organizational Performance where the statistic's T value of (2.911), and the value of (Beta) ratio was (0.13), which specifies the change of one amount in Ability to change will result in an adjustment of (0.13) amount in Organizational Performance. And therefore, the Ability to change have a positive impact on organizational performance in Drivers and Vehicles License Department (DVLD) in Jordan. In addition, Table 5 Also clarified; H1.2. Selecting BPR Methodology has a significant effect on Organizational Performance where the statistic's T value of (3.122), and the (Beta) Value ratio was (-0.05), which specifies the change of of one amount in Selecting BPR Methodology will result in an adjustment of (-0.05) amount in Organizational Performance. therefore, the Selecting BPR Methodology have a positive effect on organizational performance in Drivers and Vehicles License Department (DVLD) in Jordan.

Also, Table 5 showed; H1.3. Organizational Culture have not significant effect on organizational performance where the statistic's $T$ value of (0.237), and the value (Beta) ratio was (-0.06), which specifies the alteration of one amount in Organizational Culture will result in an adjustment of $(-0.06)$ amount in Organizational Performance. therefore, the Organizational Culture have a negative effect on Organizational Performance in Drivers and Vehicles License Department (DVLD) in Jordan. in additon, Table 5 showed; H1.4. BPR strategic alignment has not significant effect on Organizational Performance in which the statistic's T value of (1.320), and the value of (Beta) ratio was (0.00), which specifies the change of one amount in BPR strategic alignment will result in an adjustment of (0.00) amount in Organizational Performance. Thus, the BPR strategic alignment have a negative effect on Organizational Performance in Drivers and Vehicles License Department (DVLD) in Jordan.

Table 5 Also clarifies that; H1.5. Top management support has not significant effect on Organizational Performance where the statistic's T value of (0.858), and the value of (Beta) ratio was ( -0.083$)$, which specifies the alteration of one amount in Top management support will result in an adjustment of (-0.083) amount in Organizational Performance. Therefore, the Top management support have a negative effect on the organizational Performance in Drivers and Vehicles License Department (DVLD) in Jordan.

The Second, by implementing the Bootstrapping analysis in PLS software find that the rate of ( $\mathrm{T}$ value) for all Business Process Re-engineerin constructs on organizational Performance with using Information and communications technology as mediating variable. Figure 4 below represente ( $\mathrm{T}$ value) for this relation.

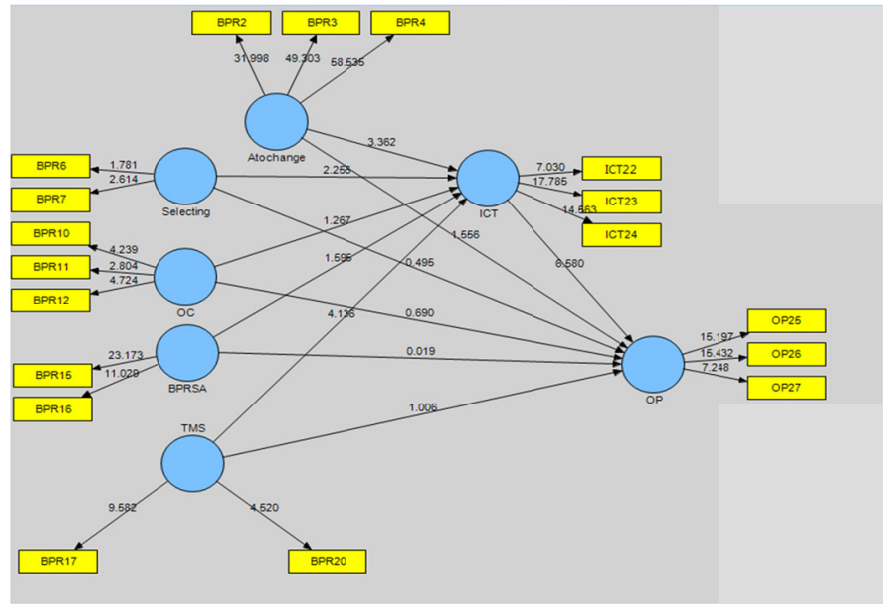

Figure 4. Business Process Re-engineerin constructs on Organizational Performance with using Information and communications technology as a mediation variable 
According to Figure 4, the researcher presented a T-value to test the hypothesis of re-engineering the five business processes as independent variables (Ability to change, Selecting BPR Methodology, Organizational Culture, BPR strategic alignment, and top management support) on Organizational Performance with using Information and communications technology as mediation variables. Thus, this relationship was found in the following three next stages:

first one: This stage shows the relations between BPR constructs (Ability to change, Selecting BPR Methodology, Organizational Culture, BPR strategic alignment, and Top management support) and Information and communications technology (See Table 6).

Table 6. Results of Business Process Re-engineerin constructs and Information and communications technology

\begin{tabular}{lll}
\hline Direct effect & T value & Beta value \\
\hline $\begin{array}{l}\text { Ability to change and Information and communications technology } \\
\text { Selecting BPR Methodology and Information and communications }\end{array}$ & 3.36 & 0.25 \\
technology & 2.25 & -0.31 \\
$\begin{array}{l}\text { Organizational Culture and Information and communications technology } \\
\text { BPR strategic alignment and Information and communications }\end{array}$ & 1.26 & 0.11 \\
technology & 1.594 & 0.12 \\
$\begin{array}{l}\text { Top management support and Information and communications } \\
\text { technology }\end{array}$ & 4.13 & 0.33 \\
\hline
\end{tabular}

Table 6 shows: H2.1. The ability to change has a great significant on Information and communications technology Where the value of $\mathrm{T}$ statistic reached (3.36), and the value of (Beta) ratio was (0.25), Which determines the amount of a single change in the ability to change that will modify $(0.25)$ in the amount in Information and communications technology. Thus, the Ability to change shows a positive effect on Information and communications technology in Drivers and Vehicles License Department (DVLD) in Jordan.

Also, Table 6 shows that; H2.2. The Selecting BPR Methodology has a high significant on Information and communications technology Where the value of $T$ statistic reached (2.25), and the value of (Beta) ratio was $(-0.31)$, which determines the amount of a single change in Selecting BPR Methodology Will cause modification of $(-0.31)$ in the amount of Information and communications technology. Thus, the Selecting BPR Methodology shows a positive effect on Information and communications technology in Drivers and Vehicles License Department (DVLD) in Jordan.

Furthermore, Table 6 shows that; H2.3. Organizational Culture has no significant in Information and communications technology Where the value of T statistic (1.26), and the value of (Beta) ratio was (0.11), which determines the amount of a single change in organizational culture Will cause modification of $(0.11)$ in the amount of Information and communications technology. Thus, the Organizational Culture shows a negative effect on Information and communications technology in Drivers and Vehicles License Department (DVLD) in Jordan.

In addition, Table 6 explained that; H2.4. BPR strategic alignment does have a significant on Information and communications technology, Where the value of T statistic reached (1.594), and the value of (Beta) ratio was (0.12), which determines the amount of a single change in BPR strategic alignment Will cause modification of $(0.12)$ in the amount in Information and communications technology. Thus, the BPR strategic alignment shows a negative effect on Information and communications technology in Drivers and Vehicles License Department (DVLD) in Jordan.

Also, Table 6 explained that; H2.5. Top management support has a significant on Information and communications technology Where the value of $\mathrm{T}$ statistic reached (4.13), and the value of (Beta) ratio was (0.33), determines the amount of a single change in Top management support will cause the modification of (0.33) in the amount of Information and communications technology. Thus, the Top management support shows a positive effect on Information and communications technology in Drivers and Vehicles License Department (DVLD) in Jordan.

Second stage: This stage shows the relations between Information and communications technology and organizational performance. As shown in table 7. 
Table 7. Test results of ICT and organizational performance

\begin{tabular}{lll}
\hline Direct effect & T value & Beta value \\
\hline ICT and Organizational Performance & 6.58 & 0.59 \\
\hline
\end{tabular}

The above table No 7 shows that: H3. Information and communications technology has a significant in organizational performance Where the value of $T$ statistic (6.58), and the value of (Beta) ratio was (0.59), determines the amount of a single change in Information and communications technology will cause the modification of (0.59) in the amount in organizational performance. Thus, the Information and communications technology it has a positive effect on Organizational Performance in Drivers and Vehicles License Department (DVLD) in Jordan.

third Stage: This stage shows the relations between BPR constructs as independent variables (Ability to change, Selecting BPR Methodology, Organizational Culture, BPR strategic alignment, and Top management support) on Organizational Performance vation as dependent variable with using Information and communications technology as a mediating variable. As shown in tables 8, 9, 10, 11 and 12 respectively.

Table 8. Test results for Ability to change and organizational performance mediating by Information and communications technology

\begin{tabular}{|c|c|c|c|c|c|}
\hline Relation & $\begin{array}{l}\text { Direct effect } \\
\text { T value }\end{array}$ & $\begin{array}{l}\text { Direct } \\
\text { effect } \\
\text { Beta }\end{array}$ & $\begin{array}{l}\text { Indirect } \\
\text { effect } \\
\text { Beta }\end{array}$ & $\begin{array}{l}\text { Total } \\
\text { effect } \\
\text { T value }\end{array}$ & $\begin{array}{l}\text { Total } \\
\text { effect } \\
\text { Beta }\end{array}$ \\
\hline Ability to change on Information and communications technology & 3.36 & 0.25 & & 3.36 & 0.25 \\
\hline $\begin{array}{l}\text { Information and communications technology on Organizational } \\
\text { Performance }\end{array}$ & 6.58 & 0.59 & & 6.58 & 0.59 \\
\hline $\begin{array}{l}\text { Ability to change on Organizational Performance mediating by } \\
\text { Information and communications technology }\end{array}$ & $\begin{array}{l}\text { Partially } \\
\text { mediate }\end{array}$ & & 0.14 & & \\
\hline $\begin{array}{l}\text { Ability to change on Organizational Performance without mediating } \\
\text { by Information and communications technology }\end{array}$ & 2.911 & 0.13 & & 3.17 & 0.27 \\
\hline
\end{tabular}

Table No 8 explained that; H4.1 ICT has a significant effect in the relationship of capacity to change and organizational performance because the ability to change has a significant effect on Information and communications technology Where the value of T statistic reached (3.36) and Information and communications technology has a significant effect on organizational performance Where the value of $\mathrm{T}$ statistic reached (6.58). Moreover, the value of (Beta) ratio for (Indirect Effect) is (0.14), which determines the amount of a single change in Ability to change and Information and communications technology will cause the modification of $(0.14)$ in the amount in organizational performance. Therefore, Information and communications technology has a partial mediation role between the ability to change and the organizational performance in the Drivers and Vehicles License Department (DVLD) in Jordan.

Table 9. Results for Selecting BPR Methodology and Organizational Performance mediating by Information and communications technology

\begin{tabular}{|c|c|c|c|c|c|}
\hline Relation & $\begin{array}{l}\text { Direct effect } \\
\text { T value }\end{array}$ & $\begin{array}{l}\text { Direct } \\
\text { effect } \\
\text { Beta }\end{array}$ & $\begin{array}{l}\text { Indirect } \\
\text { effect } \\
\text { Beta }\end{array}$ & $\begin{array}{l}\text { Total } \\
\text { effect } \\
\text { T value }\end{array}$ & $\begin{array}{l}\text { Total } \\
\text { effect } \\
\text { Beta }\end{array}$ \\
\hline $\begin{array}{l}\text { Selecting BPR Methodology on Information and communications } \\
\text { technology }\end{array}$ & 2.25 & -0.31 & & 2.25 & -0.31 \\
\hline $\begin{array}{l}\text { Information and communications technology on Organizational } \\
\text { Performance }\end{array}$ & 6.58 & 0.59 & & 6.58 & 0.59 \\
\hline $\begin{array}{l}\text { Selecting BPR Methodology on Organizational Performance mediating } \\
\text { by Information and communications technology }\end{array}$ & $\begin{array}{l}\text { Partially } \\
\text { mediate }\end{array}$ & & -0.18 & & \\
\hline $\begin{array}{l}\text { Selecting BPR Methodology on Organizational Performance without } \\
\text { mediating by Information and communications technology }\end{array}$ & 3.122 & -0.05 & & 2.39 & -0.23 \\
\hline
\end{tabular}


Table 9 clarified; H4.2 Information and communications technology has a significant effect in the relation of Selecting BPR methodology and organizational performance. because the Selecting BPR Methodology has a significant effect on Information and communications technology Where the value of $\mathrm{T}$ statistic reached (2.25) and Information and communications technology has a significant effect on organizational performance Where the value of $\mathrm{T}$ statistic reached (6.58). Furthermore, the value of (Beta) ratio for (Indirect Effect) is (-0.18), which determines the amount of a single change in Selecting BPR Methodology and Information and communications technology will cause the modification of $(-0.18)$ in the amount in Organizational Performance. Therfore, Information and communications technology is partially mediates the relationship between Selecting BPR Methodology and Organizational Performance in the Drivers and Vehicles License Department (DVLD) in Jordan.

Table 10. Test results for organizational culture and organizational performance mediating by information and communications technology

\begin{tabular}{|c|c|c|c|c|c|}
\hline Relation & $\begin{array}{l}\text { Direct } \\
\text { effect } \\
\text { T value }\end{array}$ & $\begin{array}{l}\text { Direct } \\
\text { effect } \\
\text { Beta }\end{array}$ & $\begin{array}{l}\text { Indirect } \\
\text { effect } \\
\text { Beta }\end{array}$ & $\begin{array}{l}\text { Total } \\
\text { effect } \\
\text { T value }\end{array}$ & $\begin{array}{l}\text { Total } \\
\text { effect } \\
\text { Beta }\end{array}$ \\
\hline Organizational Culture on Information and communications technology & 1.26 & 0.11 & & 1.26 & 0.11 \\
\hline $\begin{array}{l}\text { Information and communications technology on Organizational } \\
\text { Performance }\end{array}$ & 6.58 & 0.59 & & 6.58 & 0.59 \\
\hline $\begin{array}{l}\text { Organizational Culture on Organizational Performance mediating by } \\
\text { Information and communications technology }\end{array}$ & $\frac{\text { Not }}{\text { mediate }}$ & & 0.06 & & \\
\hline $\begin{array}{l}\text { Organizational Culture on Organizational Performance without } \\
\text { mediating by Information and communications technology }\end{array}$ & 0.237 & -0.06 & & 0.16 & 0.00 \\
\hline
\end{tabular}

Table 10 above clarified; H4.3 Information and communications technology has a significant effect in the relation of organizational culture and organizational performance. Because the organizational culture has no significant effect on Information and communications technology Where the value of T statistic reached (1.26) and Information and communications technology has a significant effect on organizational performance Where the value of T statistic reached (6.58). Furthermore, the value of (Beta) ratio for (Indirect Effect) is (0.06), which determines the amount of a single change in organizational culture and Information and communications technology will cause the modification of (0.06) in the amount in organizational performance. Therefore, ICT does not mediate between the organizational culture and organizational performance in the Drivers and Vehicles License Department (DVLD) in Jordan.

Table 11. Results of BPR strategic alignment and Organizational Performance mediating by Information and communications technology

\begin{tabular}{|c|c|c|c|c|c|}
\hline Relation & $\begin{array}{l}\text { Direct } \\
\text { effect } \\
\text { T value }\end{array}$ & $\begin{array}{l}\text { Direct } \\
\text { effect } \\
\text { Beta }\end{array}$ & $\begin{array}{l}\text { Indirect } \\
\text { effect } \\
\text { Beta }\end{array}$ & $\begin{array}{l}\text { Total } \\
\text { effect } \\
\text { T value }\end{array}$ & $\begin{array}{l}\text { Total } \\
\text { effect } \\
\text { Beta }\end{array}$ \\
\hline $\begin{array}{l}\text { BPR strategic alignment on Information and communications } \\
\text { technology }\end{array}$ & 1.594 & 0.12 & & 1.594 & 0.12 \\
\hline $\begin{array}{l}\text { Information and communications technology on Organizational } \\
\text { Performance }\end{array}$ & 6.58 & 0.59 & & 6.58 & 0.59 \\
\hline $\begin{array}{l}\text { BPR strategic alignment on Organizational Performance mediating by } \\
\text { Information and communications technology }\end{array}$ & $\underline{\text { Not }}$ & & 0.07 & & \\
\hline $\begin{array}{l}\text { BPR strategic alignment on Organizational Performance without } \\
\text { mediating by ICT }\end{array}$ & 1.320 & 0.00 & & 0.94 & 0.07 \\
\hline
\end{tabular}

Table 11 clarified; H4.4 Information and communications technology has a significant effect the relation of BPR strategic alignment and organizational performance. Because the BPR strategic alignment has no significant effect on Information and communications technology Where the value of T statistic reached (1.594) and Information and communications technology has significant effect on Organizational Performance Where the value of $\mathrm{T}$ statistic reached (6.58). Furthermore, the value of (Beta) ratio for (Indirect Effect) is (0.07), which 
determines the amount of a single change in BPR strategic alignment and Information and communications technology will cause the modification of (0.07) in the amount in organizational performance. Therefore, Information and communications technology is not mediate between BPR strategic alignment and organizational performance in the Drivers and Vehicles License Department (DVLD) in Jordan.

Table 12. Results for Ability to change \& Organizational Performance mediating by Information and communications technology

\begin{tabular}{|c|c|c|c|c|c|}
\hline Relation & $\begin{array}{l}\text { Direct } \\
\text { effect } \\
\text { T value } \\
\end{array}$ & $\begin{array}{l}\text { Direct } \\
\text { effect } \\
\text { Beta }\end{array}$ & $\begin{array}{l}\text { Indirect } \\
\text { effect } \\
\text { Beta }\end{array}$ & $\begin{array}{l}\text { Total } \\
\text { effect } \\
\text { T value } \\
\end{array}$ & $\begin{array}{l}\text { Total } \\
\text { effect } \\
\text { Beta } \\
\end{array}$ \\
\hline $\begin{array}{l}\text { Top management support on Information and communications } \\
\text { technology }\end{array}$ & 4.13 & 0.33 & & 4.13 & 0.33 \\
\hline $\begin{array}{l}\text { Information and communications technology on Organizational } \\
\text { Performance }\end{array}$ & 6.58 & 0.59 & & 6.58 & 0.59 \\
\hline $\begin{array}{l}\text { Top management support on Organizational Performance mediating by } \\
\text { Information and communications technology }\end{array}$ & $\begin{array}{l}\text { Fully } \\
\text { mediate }\end{array}$ & & 0.19 & & \\
\hline $\begin{array}{l}\text { Top management support on Organizational Performance without } \\
\text { mediating by Information and communications technology }\end{array}$ & 0.858 & -0.08 & & 1.06 & 0.11 \\
\hline
\end{tabular}

Table 12 expleaned: H4.2 Information and communications technology has a significant effect the relation of Top management support and Organizational Performance. Because the Top management support has significant effect on Information and communications technology Where the value of $T$ statistic reached (4.13) and Information and communications technology has a significant effect on organizational performance Where the value of T statistic reached (6.58). Moreover, Furthermore, the value of (Beta) ratio for Indirect Effect is (0.19), which determines the amount of a single change in Top management support and Information and communications technology will cause the modification of (0.19) in the amount in Organizational Performance. Therefore. Information and communications technology is completly mediated between Top management support and Organizational Performance in the Drivers and Vehicles License Department (DVLD) in Jordan.

\section{Conclusion}

The main objective of this study was to measure the effects of business process re-engineering on the Organizational Performance of Drivers and Vehicles License Department (DVLD) in Jordan. It is clear from the above results and discussion that (DVLD) in Jordan are implementing the business process re-engineering in their different operations and results are significant. The results showed that, there is a positive significant statistical effect and full mediating effect when using ICT on tp management support to improve the Organizational Performance and the ability to change and selecting BPR Methodology. On the other hand, it can also be seen that negative and non-mediating impact was found when ICTwas used on Organizational Culture and BPR strategic alignment.

Nonetheless, This study encountered some limitations that refer to new lines of research, Its main limitations relate to the study population selected,

The researcher chose one organization to conduct this study, namely the Vehicle and Driver Licensing Department (DVLD) in Jordan. This was a somewhat small sample size $(\mathrm{n}=124)$. Which may make the results concise on one organization. Therefore, the limitations and results of this paper should be noted with a view to expanding the scope of this paper to include a wider range of different samples and sectors in the future. This research paper hopes that this research will encourage other future researchers to undertake further studies about the impact of BPR on organizational performance by mediating the role of ICTs in other government sectors with a a higher sample size, and this will be very useful and will allow them to compare the results of their studies with the results of this paper.

\section{References}

AbdEllatif, M., Farhan, M. S., \& Naglaa, S. S. (2017). Overcoming business process re-engineering obstacles using ontology-based knowledge map methodology. Production and hosting by Elsevier. Future Computing and Informatics Journal, 1(22). https://doi.org/10.1016/j.fcij.2017.10.006

Abdolvand, N., Albadvi, A., \& Ferdowsi, Z. (2008). Assessing readiness for business process re-engineering. 
Business Process Management Journal, 14(4), 497-511. https://doi.org/10.1108/14637150810888046

Abubakar, H. (2016). Effects of Business Process Re-engineering on Organizational Performance: Organizational Transformation of Tour and Travel Business. Asian Journal of Applied Sciences, 4(1).

Ahadi, H. (2004). Examination of the role of organizational enablers in business process re-engineering and the impact of information technology. Information Resources Management Journal, 17(4), 1-19. https://doi.org/10.4018/irmj.2004100101

Ahmad, H., Francis, A., \& Zairi, M. (2007). Business process re-engineering: Critical success factors in higher education. Business Process Management Journal, 13, 451-469. https://doi.org/10.1108/14637150710752344

Akam, G. U., Okeke, M. N., \& Kekeocha, M. (2018). Business Process Re-engineering Resources and the Performance of Quoted Brewing Firms in Nigeria. Asian Business Research Journal, 3(1), 15-25. https://doi.org/10.20448/journal.518.2018.31.15.25

Albadvi, A., Keramati, A., \& Razmi, J. (2007). Assessing the impact of information technology on firm performance considering the role of intervening variables: Organizational infrastructures and business processes re-engineering. International Journal of Production Research, 45, 2697-2734.

Aregbeyen, O. (2011). Business Re-Engineering and Organizational Performance in Nigeria: A Case Study of First Bank Nigeria Plc. International Business Management, 5(3), 151-158. https://doi.org/10.1080/00207540600767780

Balasubramanian, S. (2010). Successful re-engineering implementation strategy: Hindustan College of engineering. Business Review, 68, 104-112.

Crowe, T. J., Fong, P. M., \& Zayas-Castro, J. L. (2002). Quantitative risk level estimation of business process re-engineering efforts. Business Process Management Journal, 8(5), 490-511. https://doi.org/10.1108/14637150210449148.

Davenport, T. H. (2008). Business process management. In V Grover and ML Markus (Eds.), Business process transformation: advances in management.

Davenport, T., \& Short, J. (1990). The new industrial engineering: information technology and business re-engineering process redesign. Sloan management review summer, 31(4), 11-27.

De Bruin, T., \& Rosemann, M. (2006). Towards understanding strategic alignment of business process management. 17th Australasian Conference on Information Systems.

Debela, T. (2009). Business process re-engineering in Ethiopian public organizations: the relationship between theory and practice. Journal of Business and Administrative Studies, 1(21). http://dx.doi.org/10.4314/jbas.v1i2.57348

Devaraj, S., \& Kohli, R. (2000). Information technology payoff in the health-care industry: a longitudinal study. Journal of Management Information Systems, 16(4), 41-67.

Fornell, C., \& Larcker, D.F.(1981). Evaluating Structural Equations Models with Unobservable Variables and Measurement Error. Journal of Marketing Research, 18(1), 39-50. https://doi.org/10.1177/002224378101800104

Gaur, A. S., \& Gaur, S. S. (2006). Statistical Methods for Practice and Research: A Guide to Data Analysis using SPSS. Thousand Oaks, California: Sage.

Hammer, M. (1990). Re-engineering work: Don't automate obliterate. Harvard.

Hammer, M., \& Champy, J. (1993). Re-engineering the corporation: a manifesto for business revolution. New York.

Isakhani A., \& Mir-Ghaderi, H. (2011). Re-engineering of business processes: analytical-executive model. Tadbir monthly journal, 165.

Kassahun, A. E., Molla, A., \& Sarkar, P. (2011). Government Process Re-engineering: What we Know and What we Need to Know. Strategic Enterprise Resource Planning Models for E-Government. Applications and Methodologies, 1. https://doi.org/10.4018/978-1-60960-863-7.ch001

Kohli, R., \& Hoadley, E. (2006). Towards developing a framework for measuring organizational impact of IT-enabled BPR: case studies of three firms. ACM SIGMIS Database, 37, 40-58. https://doi.org/10.1145/1120501.1120505 
Larsen, B. (2003). Courts of the Future; Law and Information Technology. Swedish View: An anthology produced by the IT Law Observatory of the Swedish ICT Commission. Stockholm, SOU, 112, 225-238.

Lila, R., Mansingh,., \& Osei-Bryson, K. M. (2012). Building ontology based knowledge maps to assist business process re-engineering. Decision Support Systems, 52, 577-589. https://doi.org/10.1016/j.dss.2011.10.014

Mansar, S. L., Marir, F., \& Reijers, H. A. (2003). Case-based reasoning as a technique for knowledge management in business process redesign. Electronic Journal on Knowledge Management, 1(2), 113-124.

Maull, R. S., Tranfield, D. R., \& Maull, W. (2003). Factors characterizing the maturity of BPR programs. International Journal of Operations and Production Management, 23(6), 596-624. https://doi.org/10.1108/01443570310476645

Nadeem, M., \& Ahmad, R. (2016). Impact of Business Process Re-engineering on the Performance of Banks in Pakistan. Business and Economics Journal, 7(1). http://dx.doi.org/10.4172/2151-6219.1000202

Nunnally, J. C., \& Bernstein, I. H. (1994). Psychometric Theory. New York, McGraw-Hill.

O'Neill, P., \& Sohal, A. S. (1998). Business process re-engineering: Application and success - an Australian study. International Journal of Operations \& Production Management, 18(9/10), 832-864. http://doi.org/10.1108/01443579810225487.

Ogbo, A. I., Attah, E. Y., Ewurum, U. J. F., \& Ugbam, C. O. (2015). Business process re-engineering and performance of commercial banks in North Central Nigeria. International Journal of Contemporary Applied Sciences, 2(10), 1-13.

Omidia, A., \& Khoshtinata, B. (2016). Factors affecting the implementation of business process re-engineering: taking into account the moderating role of organizational culture (Case Study: Iran Air). Procedia Economics and Finance, 36, 425-432. https://doi.org/10.1016/S22125671(16)30058-2

Ozcelik, Y. (2013). Effects of Business Process Re-engineering on Firm Performance: An Econometric Analysis. In Glykas M. (Eds.), Business Process Management: Studies in Computational Intelligence. Springer, Berlin, Heidelberg.

Reijers, H. A., \& Mansar, S. L. (2005). Best practices in business process redesign: An overview and qualitative evaluation of successful redesign heuristics. Omega, 33(4), 283-306. http://doi.org/10.1016/j.omega.2004.04.012

Salimifard, K., Abbaszadeh, M. A. (2010). Ghorbanpur. Interpretive structural modeling of critical success factors in banking process re-engineering. International Review of Business Research Papers, 6(2), 95-103.

Sekaran, U. (2006). Research Methods for Business: A Skill-Building Approach. NewYork: John Wiley And Sons, Inc.

Shaqqour, O. F., \& Al-Kassar, T. A. (2016). Studying Relationship between the Approach of Business Re-engineering and Performance "An Empirical Study on Food Companies Listed at the Amman Stock Exchange. Research Journal of Finance and Accounting, 7(12).

Skrinjar, R., Bosilj-Vuksic, V., \& Indihar-Stemberger, M. (2008). The impact of business process orientation on financial and non-financial performance. Business Process Management Journal, 14, 738-754. http://doi.org/10.1108/14637150810903084

Tka, M. \& Ghannouchia, S. A. (2012). Comparison of Business Process Models as Part of BPR Projects. Procedia Technology, 5, 427-436. https://doi.org/10.1016/j.protcy.2012.09.04

Valiris, G., \& Glykas, M. (1999). Critical review of existing BPR methodologies: The need for a holistic approach. Business Process Management Journal, 5(1), 65-86. http://doi.org/10.1108/14637159910249117

Vergidis, K., Ashutosh, T., \& Majeed, B. (2008). Business process analysis and optimization: beyond re-engineering. http://10.1109/TSMCC.2007.905812

Willcocks, L. P. (2002). How radical was IT-enabled BPR? Evidence on financial and business impacts. International Journal of Flexible Manufacturing Systems, 14, 11-31. http://doi.org/10.1023/A:1013806417513 


\section{Copyrights}

Copyright for this article is retained by the author(s), with first publication rights granted to the journal.

This is an open-access article distributed under the terms and conditions of the Creative Commons Attribution license (http://creativecommons.org/licenses/by/4.0/). 